\title{
A comparative analysis on the acceptance and use of telemedicine between physicians and patients in selected Metro Manila healthcare institutions
}

\author{
Deojon N. Elarco ${ }^{\mathrm{a}, \mathrm{i}}$, Joseph Xavier V. Mamangun ${ }^{\mathrm{b}, \mathrm{i}}$, Kyla Nhoreen R. Lescano ${ }^{\mathrm{c}, \mathrm{i}}$, \\ Adrianne Guinevere R. Lumongsudd, ${ }^{\mathrm{d}, \mathrm{i}}$, Renz Erick P. Camacho ${ }^{\mathrm{e}, \mathrm{i}}$, \\ Andre Juanito A. Domingo ${ }^{\mathrm{f}, \mathrm{i}}$, Miguel Carlos G. Arada ${ }^{\mathrm{g}, \mathrm{i}}$, \\ Emmanuelle Jericho N. Briones ${ }^{\mathrm{h}, \mathrm{i}}$
}

\author{
adeojon.elarco.pharma@ust.edu.ph, ${ }^{\mathrm{b}}$ josephxavier.mamangun.pharma@ust.edu.ph, ${ }^{\mathrm{c}}$ kylanhoreen.lescano.pharma@ust.edu.ph, \\ dadrianneguinevere.lumongsud.pharma@ust.edu.ph, renzerick.camacho.pharma@ust.edu.ph,

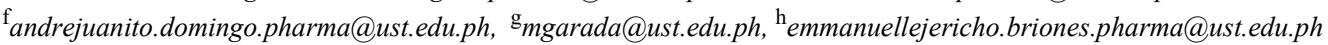 \\ ${ }^{i}$ University of Santo Tomas, Faculty of Pharmacy, Department of Medical Technology, \\ España Blvd., Sampaloc, Manila 1008 Metro Manila, Philippines
}

\begin{abstract}
Telemedicine is no longer only relevant to the geographically isolated and disadvantaged areas (GIDA). Since the COVID-19 pandemic, the Philippine government has been encouraging nationwide adoption of remote medical care to lessen the risks for both patients and healthcare workers. Its implementation, however, lacks an established framework from the government. Given these conditions, it is important to engage in studies investigating the existing acceptance and use of emerging technology such as telemedicine. This study compared the acceptance and use of telemedicine of Filipino physicians and patients in selected Metro Manila healthcare institutions. A survey questionnaire patterned from the modified Unified Theory of Acceptance and Use of Technology (UTAUT) model of Venkatesh et al. (2016) was constructed to gather data. It was deployed via Google forms to 120 respondents, including 60 physicians and 60 patients. The data gathered were then analyzed by Spearman-rank order correlation and Cramér's V for the correlation analysis, whereas descriptive statistics was used in analyzing the user groups' demographics, used and preferred modalities, and overall rating of experience in telemedicine consultation. For the physician user group, relationships between the type of hospital and facilitating conditions (FC), and computer anxiety (CA) and performance expectancy (PE) have yielded significant correlations ( $p$-value $<.05$ ). For the patient user group, relationships between the type of hospital and effort expectancy (EE), and CA and FC have significant correlations. Furthermore, both user groups exhibited significant correlations between perceived security (PS) and the four constructs of telemedicine acceptance and use, and likewise with the four constructs and behavioral intention (BI). The majority of both user groups use and prefer social media platforms in a telemedicine consultation. Moreover, data also revealed that the majority of user groups were satisfied with their telemedicine experience. Both user groups have varying factors at play on using telemedicine based on the limited data. This study sheds light on what areas of concern may be addressed for future research and policies which can improve the development of telemedicine in the country. For future studies, the researchers recommend the utilization of the structural equation modeling (SEM) statistical analysis technique to determine the moderating effects of variables involved in the study.
\end{abstract}

Keywords: telemedicine; teleconsultation; COVID-19; social media; UTAUT; Metro Manila

\section{Introduction}

Telemedicine serves as one of the technological innovations aiding in the improvement of healthcare services. The World Health Organization (WHO) $(2010)^{[1]}$ refers to it as the use of information and 
telecommunication technologies (ICT) which takes care of the patients remotely whenever the patients and healthcare professionals are not physically together. It comprises medical activities such as treatment and prevention, diagnosis, continuing education of patients and healthcare professionals, and research and evaluation (Craig \& Patterson, 2017) ${ }^{[2]}$. Its role is to offer convenience to the patient and the healthcare provider by removing the necessity to do physical visits to get treatment or medical consultation. This innovation is cost-effective, accessible, and efficient compared to consulting a doctor or other practitioner face-to-face (Boxer \& Ellimoottil, 2019) ${ }^{[3]}$. Hence, it enhances services such as patient consultations, medical education, patient monitoring, and specialty care.

The creation of telemedicine began with the purpose of treating patients who are located in remote places, far from local health facilities, or areas that do not have enough healthcare professionals. Its existence was first documented in an 1879 article published in Lancet that shows the potential use of a telephone to make doctor's appointments rather than making an unnecessary visit. Chen $(2017)^{[4]}$ stated that in 1927 , a doctor conducted a live consultation with a patient through the use of radio transmission and was coined as a "radio doctor." Later on, in the 1950s, television group therapy was achieved through satellite communications and video in remote villages of Alaska, which became a model for rural telemedicine programs. In a report made by WHO $(2010)^{[1]}$, the first-ever teleradiology system was created in 1959 wherein health personnel have used television to transmit the patient data for diagnostic radiology. The increasing use and availability of ICTs became apparent after decades of improvement in technology. This consequently led to major improvements in telemedicine services such as mobile cloud video conferencing systems (Zhang et al., 2016) ${ }^{[5]}$ and big data analytics and automated algorithms (Ting et al., 2019) ${ }^{[6]}$. As telemedicine continues to progress, it is important to understand the impact of telemedicine on patients, healthcare professionals, and the organization of care.

Healthcare professionals and patients' play key roles in the telemedicine field. They have helped in the initial growth of telemedicine by responding to the patient's desire for convenience, heavier reliance on the internet and mobile phones, and the lack of access to healthcare services (Jenkins \& Oyama, 2020) ${ }^{[7]}$. As stated by Khatun et al. $(2020)^{[8]}$, there are three notable models that serve as indicators of implementation and effectiveness of the use of new technology, namely: the Theory of Planned Behavior (TPB), the Technology Acceptance Model (TAM), and the Unified Theory of Acceptance and Use of Technology (UTAUT). The UTAUT model is considered to be the updated and most sensitive out of all models. It consists of constructs such as performance expectancy (PE), effort expectancy (EE), social influence (SI), and facilitating conditions (FC). Quantifying these components can identify the significant factors likely to influence the intention of a patient or healthcare professional in using telemedicine.

Bridging gaps in the healthcare system through telemedicine, especially those in remote areas, has been around for a long time. However, its implementation is currently more significant globally as healthcare systems try to maintain the capacity to provide service for both COVID-19patients and patients with acute and chronic complications. This mass conversion to telemedicine serves as a manifestation of it as an effective tool in changing the healthcare service landscape while protecting allied health personnel at the same time. Nonetheless, despite numerous studies and implementation experience, Bashshur et al. (2020) ${ }^{[9]}$ argue that this adoption is shortsighted. The need only rose from the current crisis and will diminish once the pandemic ends. Similarly, Pasco (2016) ${ }^{[10]}$ suggested that the Philippines' telemedicine has remained locally underutilized despite its establishment long ago since 1998. A bill has recently been proposed to expand and promote its use, especially to the underserved communities during the pandemic (Cervantes, 2020) ${ }^{[11]}$.

For the said reasons, the researchers have conducted this study which documented the comparison of existing acceptance and use of telemedicine user groups, specifically Filipino physicians and patients, in selected Metro Manila healthcare institutions during the current crisis. Identifying these experiences can explain the acceptance and use of the said technology and know if there's a similarity between the physicians' and patients' acceptance and use of telemedicine, especially that this is an emerging technological innovation in healthcare. With that said, this study can be useful for policymakers, healthcare providers, and researchers, particularly that there is the inadequacy of local studies that have high levels of evidence (Macabasag et al., 
$2016)^{[12]}$. Furthermore, as soon as the pandemic crisis has been resolved, this raises an important question: Will telemedicine still be seen as essential once the country is back to its face-to-face medical consultation? Hence, this can signify as a baseline for conducting follow-up research in a post-pandemic setting.

\subsection{Statement of the problem}

Recognizing the comparison between the physicians' and patients' acceptance and use of telemedicine served as the main problem of this research. In addition, the following sub-problems were also taken into account to generate profiles and correlations of the different variables.

1. What are the demographic variables correlated with the constructs of telemedicine and acceptance and use such as:
a. age;
b. sex;
c. type of hospital;
d. location

2. What are the contextual determinants correlated with the constructs of telemedicine acceptance and use such as:

a. Computer Anxiety (CA)

b. Perceived Security (PS)

3. What are the constructs of telemedicine acceptance and use correlated with the (Behavioral Intention) of the:
a. physicians
b. patients

4. What are the used and preferred modalities of the:
a. physicians
b. patients

5. What are the overall ratings of experience in telemedicine of the:
a. physicians
b. patients

\subsection{Objectives of the study}

\subsubsection{General objectives}

The study aimed to compare the acceptance and use of Filipino physicians and patients on the utilization of telemedicine in selected Metro Manila healthcare institutions.

\subsubsection{Specific objectives}

Specifically, this study sought:

1. To correlate the demographic variables with the constructs of telemedicine acceptance and use such as:
a. age;
b. sex;
c. type of hospital;
d. location

2. To correlate the contextual determinants with the constructs of telemedicine acceptance and use such as:

a. Computer Anxiety (CA)

b. Perceived Security (PS) 
3. To correlate the constructs of telemedicine acceptance and use with Behavioral Intention (BI) of the:
a. physicians
b. patients

4. To know the used and preferred modality in telemedicine of the:
a. physicians
b. patients

5. To determine the overall rating of experience in telemedicine of the:
a. physicians
b. patients

\subsection{Hypotheses of the study}

$H 1_{0}$ : There is no significant correlation between demographic variables and constructs of telemedicine acceptance and use for each user group.

$H 1_{\mathrm{a}}$ : There is a significant correlation between demographic variables and constructs of telemedicine acceptance and use for each user group.

$H 2_{0}$ : There is no significant correlation between contextual determinants and constructs of telemedicine acceptance and use for each user group.

$H 2_{\mathrm{a}}$ : There is a significant correlation between contextual determinants and constructs of telemedicine acceptance and use for each user group.

$H 3_{0}$ : There is no significant correlation between constructs of telemedicine acceptance and use and behavioral intention (BI) for each user group.

$H_{\mathrm{a}}$ : There is a significant correlation between constructs of telemedicine acceptance and use and behavioral intention (BI) for each user group.

\subsection{Conceptual framework}

Figure 1 exhibits the relationship of each component to the determination of telemedicine acceptance and use. To begin with, the demographic variables and contextual determinants are correlated with the constructs of telemedicine acceptance and use. When the constructs, namely, Performance Expectancy (PE), Effort Expectancy (EE), Social Influence (SI), and Facilitating Conditions (FC), have been assessed in telemedicine, their significant correlation with the users' Behavioral Intentions (BI) of adopting telemedicine can be determined. Each determinant may signify a specific aspect in telemedicine acceptance and use, influencing the respondent's BI to use telemedicine. Consequently, PE may involve perceived health management, accessibility to healthcare services, and quality of life, which can directly affect the users' intention to use telemedicine. In contrast, EE involves antecedents such as ease of use, complexity, acceptance of an innovation, and perceived ease of use which can strongly predict the users' acceptance of telemedicine.

Meanwhile, SI depends on the extent to which users' peers, colleagues, family members, and healthcare providers urge them to use telemedicine. An increase in users' acceptance and intention to use technology can be caused by positive social support. Lastly, FC includes access, availability of technical support, and organizational support (approvals from health institutions and government), promoting positive beliefs about health technology use. Comparing the significant correlations between the constructs and behavioral intention will determine the physicians' and patients' acceptance and use of telemedicine. 


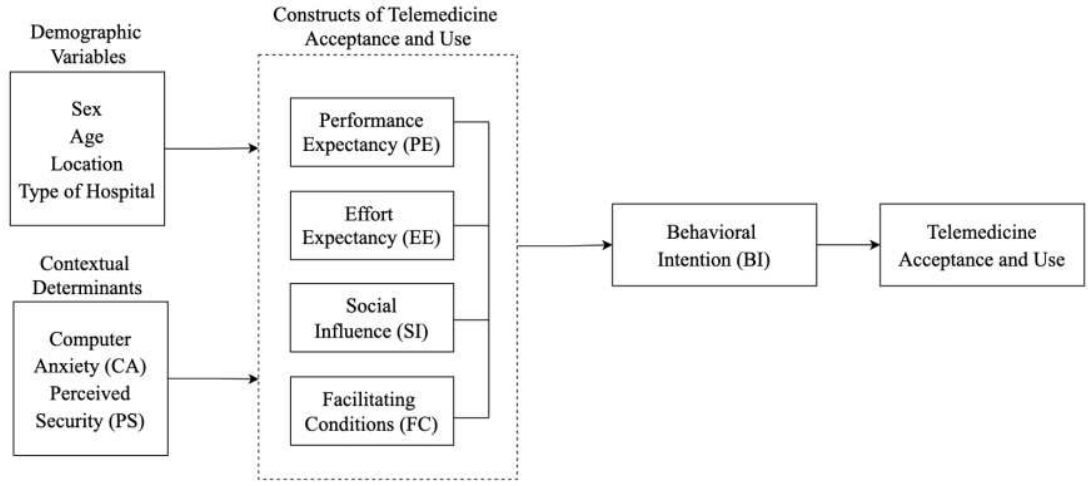

Fig. 1. Conceptual framework of the study

\subsection{Significance of the study}

The greater demand for an alternative to the conventional method of medical consultation due to the COVID-19 pandemic has justified the need for an analysis on the perceptions of the patients and physicians who currently use telemedicine as a means for communication without having to meet physically. Thus, the study will be of great benefit to the following:

For the health institutions, the study's findings will aid facilities in the proper adjustments needed to further strengthen the development and implementation of telemedicine as an effective, sustainable service for medical consultation in the Philippines. Additionally, this study could potentially assist hospitals in creating new policies and updating their online systems to enhance the quality of care provided by telemedicine in the pre-preanalytical phase.

For the public, telemedicine endeavors can assist the empowerment of remote areas by facilitating collaboration with varying healthcare professionals. Consequently, this will promote continuing health education, particularly for those in the far-flung areas.

For the study participants, the gathered data on their experiences with telemedicine may assist in the formulation of strategies to further improve the current structure and status of telemedicine in health institutions. Subsequently, this would create a better environment wherein both the patient and physician's necessities are taken into account and are accommodated.

For the researchers, the study may cover critical areas that past researchers were not able to tackle. Consequently, it instigates further discussion of telemedicine in studies in post-pandemic settings.

\subsection{Limitations of the study}

This study involves the comparative analysis of physicians' and patients' telemedicine use and acceptance and its implications in selected healthcare facilities in Metro Manila. The data was collected through a questionnaire patterned from the modified Unified Theory of Acceptance and Use of Technology (UTAUT) model of Venkatesh et al. (2016) ${ }^{[13]}$ deployed via Google Forms survey to physicians and patients with previous encounters with telemedicine, under no limitations on specific departments or specialization. Age, sex, type of hospital (whether public or private), and location are included in the demographic variables. Constructs, such as performance expectancy (PE), effort expectancy (EE), social influence (SI), and facilitating conditions (FC), contribute to the behavioral intention (BI) affecting the acceptance and use of telemedicine of the user groups. Supplementary questions on contextual determinants, used and preferred modality, and overall rating of experience were provided to contextualize the accounts of the user groups.

The survey was conducted within chosen healthcare institutions providing telemedicine, namely: University of Santo Tomas Hospital (USTH), Philippine General Hospital (PGH), Cardinal Santos Medical 
Center, Chinese General Hospital, Metropolitan Medical Center, Asian Hospital, Makati Medical Center, Medical City Ortigas, and private clinics with an estimated period of two (2) months that used a purposive sampling method for the selection of the respondents. The researchers reached out to the most accessible physicians and/or patients that may partake in the survey. The inclusion criteria for physicians are as follows: (1) Is a Filipino citizen; (2) Is at least 18 years of age but not over the age of 64; (3) Is a board-certified and licensed medical doctor in the Philippines; (4) Is based in Metro Manila; (5) Has previously encountered and used telemedicine at least once; (6) Has used telemedicine within the past 12 months. On the other hand, the patients were recruited based on the following criteria: (1) Is a Filipino citizen (2) Is at least 18 years of age but not over the age of 64; (3) Has previously encountered and used telemedicine at least once; (4) Has consulted with a physician based in Metro Manila; (5) Has used telemedicine in the past 12 months.

The primary limitation of the study was the lack of target respondents due to the hectic schedules of the physicians brought about by the pandemic, as well as the surge of COVID-19 caseload that struck the country last April 2021, making respondents unavailable during the survey timeframe, and with the telemedicine industry still at its infancy stage, as stated by Acosta et al. $(2020)^{[14]}$. The second limitation discussed the data collection process, which was conducted at a single point in time due to the limited capabilities of the researchers to survey a large number of respondents in a short amount of time. The third limitation involved the validity of the data gathered. The results interpreted would only apply to the telemedicine services provided by the selected healthcare institutions. In line with this, neither equal distribution of the respondents per health institution or clinic nor the technical and organizational infrastructure of the healthcare institutions has been covered by the study. The fourth limitation implied that the study did not collaborate with any of the respondents affiliated with their corresponding healthcare institution or the healthcare institution itself. This maintained an independent study and prevented any collective representation of their respective institutions. This also applied to the researchers being deferred to participate in the study to minimize bias in the data.

Additionally, the fifth limitation of the study concerned only the physicians and patients who have previously used telemedicine for at least one consultation or session with no requirement of utilizing a specific application or service provider. For the sixth limitation, the researchers used a non-probability-based sampling method. This sampling method implies that the study is not free from bias. The analysis for the demographic variables, contextual determinants, the four constructs, and behavioral intention (BI) was limited to identifying correlations between the variables rather than the moderating or positive effects. More so, the researchers were not able to clearly identify and generalize physicians' and patients' acceptance and use of telemedicine within the country or in any region due to the insufficient number of respondents. Thus, the results and interpretations presented in this study may only apply to the respondents. Lastly, no statistical test has been made to compare the physicians' and patients' telemedicine acceptance and use; they were solely juxtaposed.

Understanding the constructs of perceived usefulness of telemedicine can contribute to the improvements in the ongoing management of telemedicine. Significant findings from this study may empower other researchers to explore telemedicine as a tool for remote healthcare delivery and provide insight into telemedicine in healthcare facilities in the Philippines. Further studies may explore more healthcare institutions to strengthen the study's claims regarding the acceptance and use of telemedicine among Filipino physicians and patients. 


\begin{tabular}{|c|c|}
\hline Nomenclature & \\
\hline Behavioral Intention (BI) & The degree to which the physician or patient intends to use telemedicine. \\
\hline Computer Anxiety (CA) & The degree of anxiety of the physician or patient to use telemedicine. \\
\hline Effort Expectancy (EE) & The degree to which the physician or patient finds ease when using telemedicine. \\
\hline $\begin{array}{l}\text { Facilitating Conditions } \\
\text { (FC) }\end{array}$ & $\begin{array}{l}\text { The degree to which the physician or patient believes that organizational and } \\
\text { technical infrastructure exists to support the use of telemedicine. }\end{array}$ \\
\hline Infancy Stage & $\begin{array}{l}\text { This refers to the introductory phase of telemedicine, which is only starting to be } \\
\text { developed. }\end{array}$ \\
\hline Pandemic & $\begin{array}{l}\text { This refers to Coronavirus Disease-19 (COVID-19) pandemic outbreak occurring } \\
\text { concurrently with the researchers' study. }\end{array}$ \\
\hline Perceived Security (PS) & $\begin{array}{l}\text { The degree to which the physician or patient believes that using telemedicine } \\
\text { enables him or her to exchange sensitive or personal health information. }\end{array}$ \\
\hline $\begin{array}{l}\text { Performance Expectancy } \\
\text { (PS) }\end{array}$ & $\begin{array}{l}\text { The degree to which the physician or patient believes that using telemedicine will } \\
\text { help him or her better his or her job performance or health. }\end{array}$ \\
\hline User Group & $\begin{array}{l}\text { This refers to the study's respondents who are Filipino physicians or patients with } \\
\text { at least } 18 \text { years of age but not over the age of } 64 \text { who have previously used } \\
\text { telemedicine for at least one consultation within the past } 12 \text { months in selected } \\
\text { Metro Manila healthcare institutions. }\end{array}$ \\
\hline Social Influence (SI) & $\begin{array}{l}\text { The degree to which the physician or patient perceives that peers and colleagues } \\
\text { believe that he or should use telemedicine. }\end{array}$ \\
\hline Telemedicine & $\begin{array}{l}\text { The Filipino physician's provision of medical care to a Filipino patient through } \\
\text { ICT when distance or health risk is a barrier to face-to-face medical consultation. }\end{array}$ \\
\hline $\begin{array}{l}\text { Unified Theory of } \\
\text { Acceptance and Use } \\
\text { of Technology (UTAUT) }\end{array}$ & $\begin{array}{l}\text { The statistical model utilized by the researchers to determine the telemedicine } \\
\text { acceptance and use of the study's physicians and patients. }\end{array}$ \\
\hline
\end{tabular}

\section{Research elaborations}

\subsection{Research design}

This study is a quantitative cross-sectional design with an approach of a non-probability sampling method. It aimed at comparing the acceptance and use of telemedicine between the two groups, consisting of Filipino physicians and patients from selected Metro Manila healthcare institutions during the COVID-19 pandemic. The said groups were asked to answer an eight-minute survey composed of a demographic profile, a fivepoint Likert scale questionnaire, and supplementary questions. The researchers arrived with a quantitative cross-sectional design due to the nature of the study which gathered numerical data of the two groups and compared them. In addition, the limited duration of the study did not permit the researchers to use a probability sampling method. The latter method will require an exhaustive internal and external review to evaluate and approve the study, which may delay the progress of the research within the limited time frame.

\subsection{Subjects and study site}

The researchers used a purposive sampling technique to determine the target respondents of this study. These participants must be 18 to 64 years old to ensure that they are reasonable, experienced, literate, and capable enough to properly answer the questionnaire. Furthermore, this age range was chosen as the researchers considered children aged below 18 or elderly people would usually need guidance and/or parental consent. This factor was deemed difficult to verify online, especially since a signature would be required to certify it. Moreover, the specified maximum and minimum age limits were chosen according to the WHO 
$(2006)^{[15]}$ world standard population. The age groups are more standardized to evenly distribute the age proportions. Accordingly, the participants must have used telemedicine within the past 12 months. They must be knowledgeable in its use in order to ensure that they are capable and experienced enough to properly answer the survey. However, they are not limited to specific departments or specializations. Thus, those who have not used telemedicine, or are outside of the 18 to 64 age range, aren't licensed nor board-certified to be a physician are not fitting to be participants of this study. Regarding healthcare institutions, the locations were chosen for their capability to deliver telemedicine services, their telemedicine-trained medical professionals and their affiliated patients, and their accessibility to the researchers.

Moreover, they are generally hospitals and private clinics situated in Metro Manila. These include the University of Santo Tomas Hospital (USTH), Philippine General Hospital (PGH), Cardinal Santos Medical Center, Chinese General Hospital, Metropolitan Medical Center, Asian Hospital, Makati Medical Center, Medical City Ortigas, and private clinics. Of these institutions, 60 physicians and 60 patients participated in the study; overall, 120 respondents were accounted for. The researchers reached out to the most accessible physicians and/or patients that may partake in the survey without necessarily having the physician be associated with the patient or vice versa. The physicians were recruited based on the following criteria: (1) Is a Filipino citizen; (2) Is at least 18 years of age but not over the age of 64; (3) Is a board-certified and licensed medical doctor in the Philippines; (4) Is based in Metro Manila; (5) Has previously encountered and used telemedicine at least once; (6) Has used telemedicine within the past 12 months. On the other hand, the patients were recruited based on the following criteria: (1) Is a Filipino citizen (2) Is at least 18 years of age but not over the age of 64; (3) Has previously encountered and used telemedicine at least once; (4) Has consulted with a physician based in Metro Manila; (5) Has used telemedicine within the past 12 months. Both groups will be given the right to withdraw at any point in the research process.

Unlike probability-based sampling methods, the nature of the non-probability-based sampling method enabled the researchers to pre-arrange the number of patients and physicians required to be surveyed. However, this method also implies that the study is not free from bias. Therefore, the researchers will not clearly identify and generalize the physicians' and patients' acceptance and use of telemedicine within the respective region where the physicians were located, this being in Metro Manila.

\subsection{Data instrumentation}

For the instrument used in the study, the researchers developed a survey questionnaire to gather the necessary data to analyze telemedicine acceptance and use from the respondents. The questionnaire in the study was patterned from the modified UTAUT model on telemedicine acceptance and use. In addition, changes to the original questionnaire were made to fit the context of the study. The questionnaire used in the study was composed of three separate portions that are reflective of the user groups' status and experience. The demographic variables of each respondent were taken in the first portion of the questionnaire. Included in this portion are the respondent's age, sex, location, role (patient or physician), and type of hospital. The second portion of the questionnaire was composed of four categories that each tackled a construct from the modified UTAUT model, the behavioral intention (BI), and two contextual determinants.

Moreover, this section also took note of the respondent's current medium used in carrying out telemedicine. Finally, the last section of the survey tackled the respondent's overall satisfaction in using telemedicine. This was done through a five-point Likert scale, with a score of 1 denoting a very unsatisfactory experience and a score of 5 denoting a very satisfactory experience.

The survey patterned from the modified UTAUT model was composed of ratings on scale questions, wherein the respondents rate their agreement with a certain statement through a five-point Likert scale, with a score of 1 being the lowest (signifying a strong disagreement) and a score of 5 as the highest (signifying a strong agreement). This portion of the questionnaire focused on the behavioral intention (BI) of using telemedicine of the two user groups; two contextual determinants, such as Computer Anxiety (CA) and 
Perceived Security (PS); and the four constructs that influence an individual's acceptance and use to telemedicine services, such as Performance Expectancy (PE), Effort Expectancy (EE), Social Influence (SI), and Facilitating Conditions (FC). Each determinant and construct was described, wherein the corresponding definitions are as follows: (1) PE, which refers to the degree to which the physician or patient believes the use of a telemedicine platform will help him or her better his or her job performance or health; (2) EE, which focuses on the degree to which the physician or patient finds ease when using telemedicine; (3) SI, which is the degree to which the physician or patient perceives that peers and colleagues believe that he or she should use telemedicine; (4) FC, which refers to the degree to which the patient or physician believes that an organizational and technical infrastructure exists to support telemedicine use; (5) BI, which is about the degree to which the physician or patient intends to use telemedicine; (6) CA, which focuses on the degree of anxiety of the physician or patient in using telemedicine; and (7) PS, which focuses on the degree to which the physician or patient believes that using telemedicine enables him or her to exchange sensitive or personal health information.

A pilot test was conducted before the implementation of the study. The respondents who were representative of the target user groups were gathered through various online platforms, such as Twitter, Reddit, and Facebook. The validity of the questionnaire was tested using Cronbach's Alpha, which is a measure of test score reliability. It had a score of 0.91 for the physician's survey and a score of 0.89 for the patient's survey. With the baseline of acceptable scores being 0.70 , the acquired scores were considered good and acceptable. For further validation of the questionnaire, the researchers had the questionnaire analyzed and reviewed by statisticians for further suggestions, comments, and recommendations.

\subsection{Data gathering and ethical considerations}

The study was conducted on patients and physicians of the said healthcare institutions to assess and compare their acceptance and use of telemedicine. The study acquired its data by answering a quantitative survey through an online platform (Google Forms) addressed by the researchers following the Data Privacy Act of 2012. Researchers reached out to the most accessible physicians to request their participation in the research study. Respective consent letters and publication materials were distributed in search of respondents for the study. The distribution of consent letters and invitations was provided to the participating physicians through e-mail and other forms that were most convenient for them (e.g., Facebook Messenger, Viber). The letter's contents include the statement of the study's objective, general information about the study, inclusion criteria, confidentiality, data privacy, and the request for participation in the study. After gathering the data of approved consent, a letter was distributed to the participating physicians. The letter disclosed instructions regarding disseminating the survey forms to other physicians, patients, instructions on the physician-oriented survey, and the link to the Google Forms questionnaire. The physicians who express their interest in the study were provided with an instruction to disseminate the invitation of participation to their respective patients who have consulted them via telemedicine. The disclosed instructions distributed by the physicians were supplemented with publication material addressed to possible patient respondents. The publication material includes a short invitation to participate in the study, the purpose of the study, and the link and QR code to access the questionnaire. Patients who accepted the invitation may proceed to access the Google Forms questionnaire. The distributed Google Forms links included the consent letters informing respondents of the study's purpose and general concept, statement of patient voluntary participation, and confidentiality clause on the information they provided. To garner more patient respondents, researchers also posted publication materials, with their respective captions, across different social media sites such as Facebook, Twitter, and Reddit. After successfully completing the survey forms, the researchers proceeded with the data cleaning, processing, analysis, and interpretation. Any form of personal information provided by the respondents is kept anonymous in line with the confidentiality and privacy conditions of the study.

In line with the data gathering procedure, ethical principles were carefully observed and given to the 
respondents with utmost respect throughout the research. The researchers humbly asked the physicians' and patients' participation to become respondents of the study. The researchers did not pressure nor coerce potential respondents to participate in the study's survey. Before the survey proper, the respondents were provided with a consent form that includes information about the researchers, the purpose and objectives of the study, and the setback and benefits of participating. The contact details of the researchers were added to the informed consent form if questions arise. The respondents were given autonomy, the right to refuse participation, and to withdraw from the study. In accordance with the Data Privacy Act of 2012, the researchers ensured that the respondents' information was kept private and confidential. The data was handled discretely and used only within the scope of academic research. Due to the situation in our country brought about by the pandemic, the survey was conducted online so that the respondents would not be subjected to any risk. To ensure and protect data privacy and confidentiality, the accessibility of the data collected was limited to the researchers, statisticians, and thesis advisers. All information gathered in the study's data collection was disposed of and deleted at the end of the research study. The researchers, and their statisticians and thesis adviser, who have had access to the data during the study, were prohibited from retrieving any of the gathered data.

Before conducting the survey proper, necessary documents were submitted to the Faculty of Pharmacy Ethics Committee (FOPREC) for evaluation. The said committee has approved the research for implementation in compliance with scientific content writing and ethical standards of research.

\subsection{Data analysis}

The researchers have conducted a quantitative analysis. First, the sample size was considered using nonprobability sampling, specifically the purposive sampling technique. Then, with the help of their statisticians, the researchers utilized R Software and Microsoft Excel in treating the data gathered for the study. The demographic profiles, used and preferred modalities of telemedicine, and overall experience rating have been analyzed using descriptive statistics. As for the data from the five-point Likert scale, these were analyzed using mean. In addition, the researchers used the Spearman rank-order correlation to measure the degree of association for the age of the respondents against the constructs of telemedicine acceptance and use; contextual determinants, such as CA and PS, against the constructs of telemedicine acceptance and use; and the constructs of telemedicine acceptance and use against the behavioral intention (BI). Additionally, Cramér's V was used to measure the degree of association between the sex, type of hospital, and location against the constructs of telemedicine acceptance and use.

\section{Results or findings}

The objective of this study was to compare the acceptance and use of telemedicine between physician and patient user groups in selected Metro Manila healthcare institutions. This chapter includes the presentation of results, statistical analysis, and interpretation of the data gathered throughout the course of study in order to arrive with the answers to the problems presented in Chapter 1. Data analysis was done through the utilization of Spearman-rank order correlation, Cramér's V, and descriptive statistics. The level of correlation is based on the study of Meghanathan (2016) ${ }^{[16]}$, where the study's table regarding the range of correlation coefficient values and the corresponding levels of correlation is displayed as Table 9 in Appendix B. 


\subsection{Demographic profile}

Table 1. Demographic Profile of the User Groups

\begin{tabular}{|c|c|c|c|c|}
\hline \multirow{2}{*}{ Demographics } & \multicolumn{2}{|c|}{ Physicians } & \multicolumn{2}{|c|}{ Patients } \\
\hline & Count & Percentage (\%) & Count & Percentage $(\%)$ \\
\hline \multicolumn{5}{|l|}{ Sex } \\
\hline Female & 34 & $57 \%$ & 45 & $75 \%$ \\
\hline Male & 26 & $43 \%$ & 15 & $25 \%$ \\
\hline \multicolumn{5}{|l|}{ Age } \\
\hline $18-24$ years old & 1 & $2 \%$ & 29 & $48 \%$ \\
\hline 25-34 years old & 7 & $12 \%$ & 14 & $23 \%$ \\
\hline $35-44$ years old & 23 & $38 \%$ & 10 & $17 \%$ \\
\hline $45-54$ years old & 26 & $43 \%$ & 7 & $12 \%$ \\
\hline 55-64 years old & 3 & $5 \%$ & - & - \\
\hline \multicolumn{5}{|l|}{ Location } \\
\hline Urban area & 60 & $100 \%$ & 49 & $82 \%$ \\
\hline Rural area & - & - & 11 & $18 \%$ \\
\hline \multicolumn{5}{|l|}{ Type of Hospital } \\
\hline $\begin{array}{l}\text { Private } \\
\text { hospital/Private clinic }\end{array}$ & 52 & $87 \%$ & 53 & $88 \%$ \\
\hline Public hospital & 6 & $10 \%$ & 7 & $12 \%$ \\
\hline $\begin{array}{l}\text { Private } \\
\text { hospital/Private } \\
\text { clinic, Public hospital }\end{array}$ & 2 & $3 \%$ & - & - \\
\hline
\end{tabular}

The first part of the questionnaire looked into the demographic profile of the 120 study respondents, composed of an equal number of physicians (50\%) and patients (50\%). Table 1 shows that the majority of the patient-user group are female (75\%), belong to the $18-24$ years old age group $(48 \%)$, used telemedicine in an urban area $(82 \%)$, and have been accommodated by a private hospital/private clinic $(88 \%)$. Whereas for the physician user group, the majority are female (57\%), belong to the $45-54$ years old age group (43\%), used telemedicine in an urban area $(100 \%)$, and provided the telemedicine service under a private hospital/private clinic (87\%). 


\subsection{Correlation between demographic variables and constructs of telemedicine acceptance and use}

Tables 2.1 and 2.2, as shown in Appendix A, present the correlations between demographic variables and the constructs of telemedicine acceptance and use for both user groups. Demographic variables involved in this study, such as age, sex, location, and type of hospital, are against the constructs of telemedicine acceptance and use namely: Performance Expectancy (PE), Effort Expectancy (EE), Social Influence (SI), and Facilitating Conditions (FC), wherein the level of correlation between constructs and variables were identified through Spearman rank-order correlation and Cramér's V. Specifically, the correlations between age and the constructs of telemedicine acceptance and use was analyzed through Spearman rank-order correlation while Cramér's V was utilized for the analysis of correlations between the sex, type of hospital, and location and 63 the constructs of telemedicine acceptance and use. Table 2.1 portrays the correlation between the variables and the constructs for the physician user group while Table 2.2 indicates the correlation between variables and constructs for the patient user group. For instance, in Table 2.1, a significant moderate positive correlation has been noted between the Type of Hospital and $\mathrm{FC}(\varphi \mathrm{c}=0.599, \mathrm{p}$-value $<.05)$ for the physician user group. In contrast, the patient user group demonstrated a significant strong positive correlation between the Type of Hospital and EE $(\varphi c=0.602$, $p$-value $<.05)$, as shown in Table 2.2. As for the remaining unstated correlations between the demographic variables and constructs of telemedicine acceptance and use for both user groups, these have shown no significance ( $p$-value $>.05$ ), ranging from a very weak negative correlation to a moderate positive correlation.

\subsection{Correlation between contextual determinants and constructs of telemedicine acceptance and use}

Table 3. Correlation between Computer Anxiety (CA) and the Constructs of Telemedicine Acceptance and Use

\begin{tabular}{|c|c|c|c|c|c|c|}
\hline Constructs & $\rho$ & Level of Correlation & $p$-value & $\rho$ & Level of Correlation & $p$-value \\
\hline $\mathrm{PE}$ & 0.3094 & Weak Positive & $0.01614^{*}$ & 0.0064 & Very Weak Positive & 0.961 \\
\hline $\mathrm{EE}$ & 0.2125 & Weak Positive & 0.1032 & 0.0565 & Very Weak Positive & 0.6684 \\
\hline $\mathrm{FC}$ & 0.1467 & Very Weak Positive & 0.2633 & 0.3305 & Weak Positive & $0.009902 *$ \\
\hline
\end{tabular}

*Significant at $p<.05$

Table 3 demonstrates the correlation between the contextual determinant Computer Anxiety (CA), and the constructs of telemedicine acceptance and use. In order to determine the correlation between the listed data of Table 3, Spearman rank-order correlation was performed, wherein a p-value $<.05$ illustrates a significant correlation. For the physician user group, a significant weak positive correlation was demonstrated between PE and CA $(\rho=.3094, p$-value $<.05)$. On the other hand, the patient user group demonstrated a significant weak positive correlation between FC and CA $(\rho=.3094$, p-value $<.05)$. 
Table 4. Correlation between Perceived Security (PS) and the Constructs of Telemedicine Acceptance and Use

\begin{tabular}{ccccccc}
\hline \multirow{2}{*}{ Constructs } & \multicolumn{2}{c}{ PS $_{\text {Physicians }}$} & \multicolumn{3}{c}{ PS $_{\text {Patients }}$} \\
\cline { 2 - 7 } & $\boldsymbol{\rho}$ & $\begin{array}{c}\text { Level of } \\
\text { Correlation }\end{array}$ & $\boldsymbol{p}$-value & $\boldsymbol{\rho}$ & $\begin{array}{c}\text { Level of } \\
\text { Correlation }\end{array}$ & $\boldsymbol{p}$-value \\
\hline PE & 0.4734 & Weak Positive & $0.000134^{*}$ & 0.6912 & Strong Positive & $0.0000000009765^{*}$ \\
EE & 0.6416 & Strong Positive & $0.00000003308^{*}$ & 0.5932 & Moderate positive & $0.0000005886^{*}$ \\
SI & 0.2780 & Weak Positive & $0.03152^{*}$ & 0.5252 & Moderate Positive & $0.00001644^{*}$ \\
FC & 0.5542 & Moderate Positive & $0.00000434^{*}$ & 0.5688 & Moderate Positive & $0.000002125^{*}$ \\
\hline PE: Performance Expectancy, EE: Effort Expectancy, SI: Social Influence, FC: Facilitating Conditions, PS: Perceived Security & & & &
\end{tabular}

*Significant at $p<.05$

Table 4 displays the correlations between the contextual determinant Perceived Security (PS), and the constructs of telemedicine acceptance and use. Spearman rank-order correlation was also utilized in the analysis of this correlation. As displayed in Table 4, all of the constructs of telemedicine acceptance and use exhibited a significant positive correlation with PS for both user groups, ranging from weak positive correlations to strong positive correlations. Two of the notable correlations are a significant strong positive correlation in the physician user group between EE and PS $(\rho=.6416$, $p$-value $<.05)$, and a significant strong positive correlation in the patient user group between PE and PS $(\rho=.6912$, p-value $<.05)$.

\subsection{Mean score of the questionnaire items}

Table 5. Mean Score of the Questionnaire Items

\begin{tabular}{|c|c|c|c|}
\hline Item & Mean $_{\text {Physician }}$ & Mean Patient $_{\text {P }}$ & Statement \\
\hline \multicolumn{4}{|c|}{ PE: The degree to which an individual believes that using the system will help him to attain gains in job performance } \\
\hline PE1 & 4.3333 & 4.4167 & I find telemedicine useful for my consultation. \\
\hline PE2 & 2.7000 & 3.1667 & $\begin{array}{l}\text { I find telemedicine more efficient when it comes to communication than face-to-face } \\
\text { consultation. }\end{array}$ \\
\hline PE3 & 3.9000 & 3.9333 & I find telemedicine helpful in increasing my productivity. \\
\hline PE4 & 4.2500 & 4.4167 & $\begin{array}{l}\text { I find telemedicine more advantageous due to expenses, convenience, no need for travel, safety, } \\
\text { etc. }\end{array}$ \\
\hline PE1-4 & 3.7958 & 3.9833 & \\
\hline \multicolumn{4}{|c|}{ EE: The degree to which an individual believes that a telemedicine is easy to use } \\
\hline EE1 & 3.6833 & 3.8500 & I find my interaction clear and understandable while using telemedicine. \\
\hline EE2 & 3.9333 & 4.0167 & I find it easy to become skillful in using telemedicine. \\
\hline EE3 & 4.2833 & 4.3833 & I find telemedicine easy to use. \\
\hline EE4 & 4.3000 & 4.3333 & I find operating telemedicine easy to learn. \\
\hline EE1-4 & 4.0500 & 4.1458 & \\
\hline \multicolumn{4}{|c|}{ SI: The degree to which an individual considers that important/influential people believe that he/she should use telemedicine } \\
\hline SI1 & 3.3500 & 3.2000 & Influential people suggest that I should use telemedicine. \\
\hline SI2 & 3.8333 & 3.7833 & People who are important to me think that I should use telemedicine. \\
\hline SI3 & 3.6333 & 3.7833 & A telemedicine company or employer has been helpful in using telemedicine. \\
\hline SI4 & 3.3500 & 3.2000 & My local/national government has supported the use of telemedicine. \\
\hline SI1-4 & 3.5417 & 3.4917 & \\
\hline \multicolumn{4}{|c|}{$\begin{array}{l}\text { FC: The degree to which an individual believes that there is an existing } \\
\text { organization and technical infrastructure to support telemedicine use }\end{array}$} \\
\hline FC1 & 4.2833 & 4.5500 & $\begin{array}{l}\text { I have the resources such as finances, electricity, device, and fast, reliable internet access or } \\
\text { network signal necessary to use telemedicine. }\end{array}$ \\
\hline
\end{tabular}




\begin{tabular}{|c|c|c|c|}
\hline FC2 & 4.4167 & 4.2833 & I have adequate knowledge to use telemedicine. \\
\hline FC3 & 3.7000 & 4.0000 & I believe that telemedicine can be an alternative to routine face-to-face consultation. \\
\hline FC4 & 3.5500 & 3.5667 & $\begin{array}{l}\text { I believe that technical support is available to assist me whenever I have difficulties in using } \\
\text { telemedicine. }\end{array}$ \\
\hline FC1-4 & 4.1000 & 3.9875 & \\
\hline \multicolumn{4}{|c|}{ BI: The degree to which an individual intends to use a telemedicine platform. } \\
\hline BI1 & 4.3333 & 4 & I intend to use telemedicine in the next six (6) months. \\
\hline BI2 & 4.3667 & 4.1 & I predict I will use telemedicine in the next six (6) months. \\
\hline $\mathrm{BI} 3$ & 4.3167 & 3.8833 & I plan to use telemedicine in the next six (6) months. \\
\hline BI1-3 & 4.3389 & 3.9944 & \\
\hline \multicolumn{4}{|c|}{ CA: The anxiety to use information and communications technology-based services. } \\
\hline CA1 & 4.5333 & 4.1833 & $\begin{array}{l}\text { I believe that anyone can learn to use a device (e.g., computer, cell phone, tablet, etc.) if they are } \\
\text { patient and motivated. }\end{array}$ \\
\hline CA2 & 1.9667 & 1.8833 & $\begin{array}{l}\text { I hesitate to use a device (e.g., computer, cell phone, tablet, etc.) for fear of making mistakes and } \\
\text { having consequences. }\end{array}$ \\
\hline CA3 & 4.3333 & 4.1500 & $\begin{array}{l}\text { I would like to learn about and use a device (e.g., computer, cell phone, tablet, etc.) if given the } \\
\text { opportunity. }\end{array}$ \\
\hline CA4 & 4.7167 & 4.7333 & $\begin{array}{l}\text { I feel devices (e.g., computer, cell phone, tablet, etc.) are necessary tools in both educational and } \\
\text { work settings. }\end{array}$ \\
\hline CA1-4 & 3.8875 & 3.7375 & \\
\hline \multicolumn{4}{|c|}{ PS: The degree to which using information technology enables the users to exchange sensitive/personal health information } \\
\hline PS1 & 3.5167 & 3.5500 & $\begin{array}{l}\text { I would feel secure exchanging health information using the Internet and devices (e.g. computer, } \\
\text { cell phone, tablet, etc.). }\end{array}$ \\
\hline PS2 & 3.3667 & 3.5667 & $\begin{array}{l}\text { I believe that telemedicine offers a secure means through which to send sensitive health } \\
\text { information. }\end{array}$ \\
\hline PS3 & 3.3833 & 3.5167 & I would feel totally safe providing sensitive health information over telemedicine. \\
\hline PS4 & 3.3667 & 3.4833 & $\begin{array}{l}\text { I believe that using devices (e.g., computer, cell phone, tablet, etc.) and an internet connection is } \\
\text { a safe way to transmit sensitive health information. }\end{array}$ \\
\hline PS1-4 & 3.4083 & 3.5292 & \\
\hline
\end{tabular}

Table 5 presents the items used in the survey questionnaire, the item description, and the mean score of both user groups for each measured item. For the physician user group, the mean values ranged from 3.4083 to 4.3389 , whereas the mean values of the 67 patient-user group had a range of 3.4917 to 4.1458 . The questionnaire portion was composed of 27 items representing the four constructs of telemedicine acceptance and use, the behavioral intention (BI), and the two contextual determinants.

\subsection{Correlation between constructs of telemedicine acceptance and use and behavioral intention}

Table 6. Correlation between Constructs of Telemedicine Acceptance and Use and Behavioral Intention (BI)

\begin{tabular}{|c|c|c|c|c|c|c|}
\hline \multirow{2}{*}{ Constructs } & \multicolumn{3}{|c|}{ BI Physicians } & \multicolumn{3}{|c|}{ BI $\mathbf{I}_{\text {Patients }}$} \\
\hline & $\rho$ & Level of Correlation & $p$-value & $\rho$ & Level of Correlation & $p$-value \\
\hline $\mathrm{PE}$ & 0.5116 & Moderate Positive & $0.0000295^{*}$ & 0.4808 & Moderate Positive & $0.000101 *$ \\
\hline $\mathrm{EE}$ & 0.3171 & Weak Positive & $0.01355^{*}$ & 0.3817 & Weak Positive & $0.002617 *$ \\
\hline SI & 0.3980 & Weak Positive & $0.001639 *$ & 0.2931 & Weak Positive & $0.02304 *$ \\
\hline $\mathrm{FC}$ & 0.4746 & Moderate Positive & $0.000128 *$ & 0.4681 & Moderate Positive & $0.000162 *$ \\
\hline
\end{tabular}

*Significant at $p<.05$ 
Table 6 displays the correlation from both user groups between constructs of telemedicine acceptance and use and BI. For the analysis of correlations, Spearman rank-order correlation was utilized. The four constructs displayed significant correlations to the BI in both user groups, wherein p-value $<.05$ was obtained for all the analyzed correlations. Moreover, two of the four constructs displayed significant moderate positive correlations for both physicians and patients. For example, the physician user group exhibited significant moderate positive correlations between PE and BI $(\rho=.5116$, p-value $<.05)$, and FC and BI $(\rho=.4746$, pvalue $<.05)$. Similarly, the 68 patient-user group exhibited significant moderate positive correlations between $\mathrm{PE}$ and $\mathrm{BI}(\rho=.4808$, $\mathrm{p}$-value $<.05)$, and $\mathrm{FC}$ and $\mathrm{BI}(\rho=.4681, \mathrm{p}$-value $<.05)$.

\subsection{Preferred and used modalities in telemedicine}

Table 7. Count and Percentage Distribution of Used and Preferred Modality in Telemedicine

\begin{tabular}{|c|c|c|c|c|}
\hline \multirow{2}{*}{ Response } & \multicolumn{2}{|c|}{ Physicians } & \multicolumn{2}{|c|}{ Patients } \\
\hline & Count & Percentage (\%) & Count & Percentage $(\%)$ \\
\hline \multicolumn{5}{|c|}{ Mode/s of Communication Used in Telemedicine } \\
\hline Telephone & 24 & $40 \%$ & 15 & $25 \%$ \\
\hline Text Messaging & 24 & $40 \%$ & 23 & $38 \%$ \\
\hline E-mail & 20 & $33 \%$ & 20 & $33 \%$ \\
\hline Video Conferencing App & 30 & $50 \%$ & 21 & $35 \%$ \\
\hline Social Media Platform & 46 & $77 \%$ & 36 & $60 \%$ \\
\hline Telemedicine App & 30 & $50 \%$ & 22 & $37 \%$ \\
\hline \multicolumn{5}{|c|}{ Preferred Mode/s of Communication in Telemedicine } \\
\hline Telephone & 14 & $23 \%$ & 16 & $27 \%$ \\
\hline Text Messaging & 9 & $15 \%$ & 14 & $23 \%$ \\
\hline E-mail & 7 & $12 \%$ & 13 & $22 \%$ \\
\hline Video Conferencing App & 25 & $42 \%$ & 35 & $58 \%$ \\
\hline Social Media Platform & 38 & $63 \%$ & 36 & $60 \%$ \\
\hline Telemedicine App & 20 & $33 \%$ & 25 & $42 \%$ \\
\hline
\end{tabular}

Table 7 demonstrates both user groups' used modes of telemedicine and preferred modes of telemedicine. The resulting count and percentages would not equate to 60 respondents per group or to a hundred percent since both user groups were allowed to select numerous options among the given modalities. The table illustrates that most physicians used a social media platform when conducting telemedicine (77\%). Likewise, most of the patient-user group used a social media platform for telemedicine $(60 \%)$. Contrarily, the modality selected the least amount of times for the physician user group is e-mail (33\%), while the patient user group has chosen the modality of consulting through telephone $(25 \%)$ the least amount of times. 
As for the preferred mode of telemedicine, most of the physician user group has chosen the social media platform $(63 \%)$ as their preferred mode of telemedicine. In contrast, most of the patients have chosen video conferencing applications (58\%) and social media platforms (60\%) as their preferred modes. Moreover, text messaging and e-mail are the two methods selected the least amount of times for the preference of both user groups.

\subsection{Overall rating of experience}

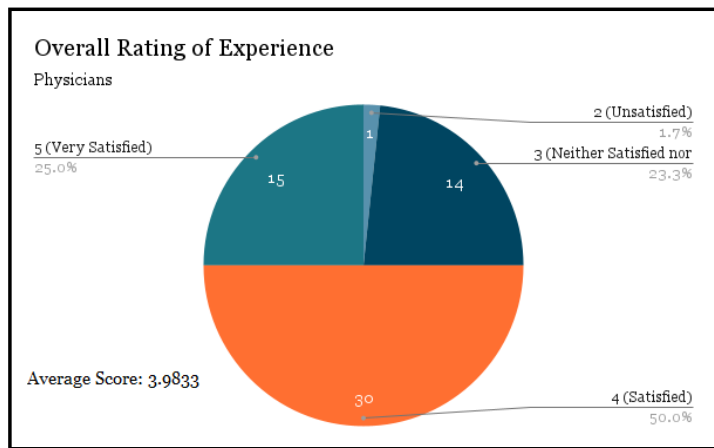

Fig 2. Overall Rating of Experience of the Physician User Group

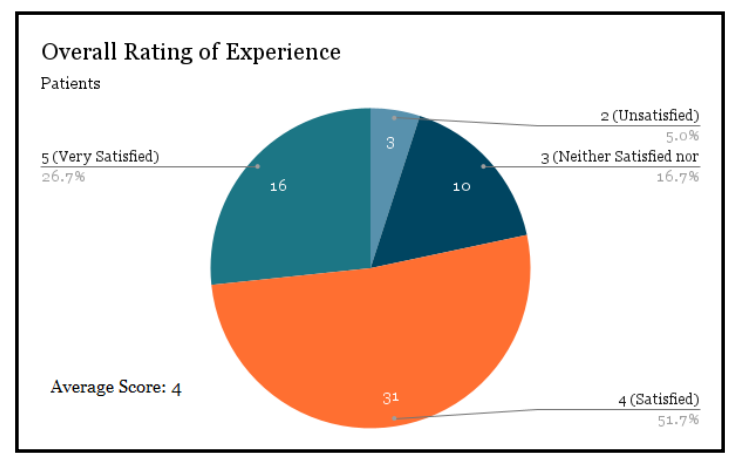

Fig 3. Overall Rating of Experience of the Patient User Group

Table 8. Average of Overall Rating of Experience of the User Groups

\begin{tabular}{cc}
\hline User Groups & Average \\
\hline Physician & 3.9833 \\
Patient & 4 \\
\hline TOTAL & 3.9917 \\
\hline
\end{tabular}

Figures 2 and 3 exhibit the overall rating of experience in using telemedicine. It shows that half of the physicians' overall rating of experience is $4(50 \%)$. Similarly, the majority of patients' overall rating of experience is $4(52 \%)$. Furthermore, a rating of $5 \mathrm{had}$ the 2 nd highest frequency in both user groups. Thus, the 
average overall rating of experience for both user groups is at 3.9917 , as presented in Table 8 . This indicates that most respondents are satisfied with their experience in using telemedicine in the past 12 months.

\subsection{Discussion}

Telemedicine has become an essential healthcare delivery system for remote diagnosis, treatment, and triage processes especially in the time of COVID-19 pandemic. The questionnaire in this study was patterned from the Unified Theory of Acceptance and Use model to explain the actual use of the technology or system, as well as the incorporated factors and methods that affect human behavior theory. The correlation of the demographic variables, contextual determinants, and constructs of user acceptance and usage of emerging technology, such as telemedicine are of great significance in determining the user's perspective and needs for a better service. Moreover, the researchers added supplementary questions which tackled the used and preferred modalities of telemedicine and the overall rating of experience of the respondents.

The correlations between the demographic variables and constructs of telemedicine acceptance and use reveal that the type of hospital is associated with the physicians' Facilitating Condition (FC), and also the patients' Effort Expectancy (EE), as demonstrated in Table 2. This could be attributed to the data displayed in Table 1, wherein most user groups have the option of a private hospital selected as the type of hospital in which interaction through telemedicine is performed. To elaborate, the physicians who have provided their telemedicine services under private hospitals correlate with FC since most of them agree with the FC, as shown in Table 5. To an extent, their agreement implies that they believe that an organizational and technical infrastructure exists to support their use of telemedicine. These infrastructures come in the form of resources, i.e., varying modes of telemedicine, internet access, and devices, which they have adequate knowledge about; and in turn, these eliminate the barriers to use telemedicine (Venkatesh et al., 2003) ${ }^{[17]}$. As for most patients who have been provided with telemedicine service under a private hospital, they have a correlation with EE for they believe that ease is associated with telemedicine. Taking into account the modes of telemedicine used by the patients, as shown in Table 7, infer that they have different means on how to use telemedicine for their convenience. The claims asserted for each user group can be supported with the estimated mean score of 4 for the physician user group's FC. As for the estimated mean score of 4 for the patient user group's EE is shown in Table 5. Both of these estimated mean scores signify that the user groups involved with the private hospital can relate with the implication of believing in the FC and EE, respectively. Based on the limited data, there is a significant correlation between the demographic variable, specifically the type of hospital, and constructs of telemedicine acceptance and use, such as FC and EE, for the physician and patient user group, respectively. Thus, $H 1_{\mathrm{a}}$ was accepted. However, it is important to note that due to the skewed distribution of private hospitals versus the other types, the researchers cannot broadly apply this to the whole population of Metro Manila.

In Table 3, the correlation between Computer Anxiety (CA) and the constructs of telemedicine acceptance and use shows that there is a significant weak positive correlation between CA and PE in the physician user group. CA is an important factor when a user group judges new technological services. It is the anxiety to use information and communications technology-based services. This may indicate that CA is correlated to the user's perception of the usefulness of using telemedicine. In the study of Tsai et al. (2019) ${ }^{[18]}$, they indicated that as anxiety increases, the individual's perception of perceived usefulness decreases. In other words, when the user is nervous or afraid of using telemedicine, it will negatively affect the future use of telemedicine. It will further lower their perception of the perceived usefulness of telemedicine. In addition, the data on the patient user group shows that there is a significant weak positive correlation between CA and FC. This can also be supported by the study of Tsai et al. (2019) ${ }^{[18]}$, where the researchers indicated that the elderly will be scared of using new technology when they are not knowledgeable in using these technologies. Furthermore, they presented that transition cost is one reason why the patients are hesitant to use the new telemedicine services. Therefore, one can expect that if a patient takes a lot of time and resources to learn the new service, 
the patient will prefer to stay in their traditional ways. Therefore, the correlation between CA and PE for the physician user group and CA and FC for the patient-user group were significant and support the alternative hypothesis $\left(H 2_{\mathrm{a}}\right)$.

Consumer privacy and information are important aspects of any business and program, especially those in relation to health and private information such as telemedicine, like Hall and McGraw (2014) ${ }^{[19]}$ stated. Without the presence of adequate security measures and information bylaws, the consumers, both physicians, and patients, would, of course, tend to doubt not only the company but the technology itself. This phenomenon is adequately seen in this study, wherein on the topic of Perceived Security (PS) and their relation to the use and acceptance of telemedicine in Table 4, a significantly positive correlation between it and all the constructs was observed. Furthermore, a systematic review of telemedicine security across 58 journal articles by Garg and Brewer $(2011)^{[20]}$ found that privacy and data integrity was the most prevalent issue discussed in the articles, thus exhibiting the need to improve the standardization of telemedicine security in general. This issue is also present in the Philippines, as stated by a study conducted by Leochico, Espiritu, Ignacio, and Mojica (2020) ${ }^{[21]}$, where they found that data security issues and the ensuing data privacy concerns were one of the more prevalent problems found in the use of telemedicine. To improve cybersecurity in general, an article by Jalali et al. $(2020)^{[22]}$ stated that though cybersecurity is a complex and multidisciplinary field, awareness is the first and most important step to follow for all those working in and on telemedicine whether it be through education, employee training, and cyberattack simulations. They further elaborated that important cybersecurity measures to follow include "encrypting data, keeping software updated, running antivirus software, using 2-factor authentication, and following local cybersecurity regulations or recommendations." Thus, the researchers have accepted $H 2_{a}$ through these findings since PS had a significant correlation to the four constructs of telemedicine acceptance and use in both user groups.

Based on Table 6, all four constructs were significantly correlated to the behavioral intention (BI) in both user groups. A study by Kohnke et al. $(2014)^{[23]}$ revealed that clinicians who presented a positive attitude towards telemedicine had increased the likelihood of adopting the technology. This strengthens the idea that there is a positive correlation between BI and the constructs of telemedicine acceptance and use. In particular, a study on diabetes patients shows that Performance Expectancy (PE) is the most important determinant influencing the use of diabetes management applications (Zhang et al., 2019) ${ }^{[24]}$. Patients who believe that they may greatly benefit from the technology were more open to utilizing and accepting these technologies. As used in the study, PE is a construct that addresses how a physician or patient believes that using telemedicine will allow them to receive benefits from it. The findings from this study may support the idea that promoting telemedicine to extend medical services to rural areas from experts, usually from urban areas, would establish an achievable benefit from telemedicine and allow user groups to accept these technologies.

Followed by PE, FC also showed significant moderate positive correlations to BI on both user groups. The said construct is defined as the perceived ease in using a technology that could be influenced by factors such as resource availability, connectivity infrastructures, service-supporting measures, and platforms. Similar findings were observed in the study of Cimperman et al. (2016) ${ }^{[25]}$, which implied that the government's support and policies, as well as health professional recommendations and guidance, were likely to promote favorable beliefs about the use of technology in health thus, increasing patients' willingness to use online medical services. Moreover, access and availability of technical and organizational resources such as telemetric devices, good internet connection, and other facilities were prerequisites attributed to the widespread adoption of telemedicine (Adenuga et al., 2017) ${ }^{[26]}$. According to Fernandez-Marcelo et al. $(2016)^{[27]}$, the Philippine government plays a critical role in improving national information and communication technology (ICT) infrastructure in telehealth (e.g., infrastructure for internet connectivity), especially for people residing in remote and disadvantaged areas. The government must also formulate an enabling environment that could engage private sectors in telehealth and other social services. Telemedicine could be supported and facilitated by the readiness of resources. The cost of telemedicine will not be considered a burden if proper and adequate resources are provided (Techatraiphum et al., 2016) ${ }^{[28]}$. With 
restricted access to healthcare services due to fully occupied public health offices and hospitals, telemedicine would be essential in extending assistance to the public. Improvement of facilities and services could promote telemedicine use for both user groups.

Meanwhile, EE is described as the perceived amount of effort exerted in using a system or technology wherein the study's results reveal a correlation for both user groups' BI for telemedicine. This relationship can be supported from a study by Sun et al. (2013) ${ }^{[29]}$, where user groups, who infer that they have adequate knowledge or competency when introduced to technology, were not hindered by the effort needed to use telemedicine and become inclined to its acceptance. On the other hand, user groups who perceive themselves as unskilled or those who might find difficulty learning new technology would find the degree of ease of use as a determinant of their acceptance of new technologies. Despite the significance presented, the results, as shown in Table 6, reveal that the correlation between EE and BI only indicated a weak positive relationship for both user groups. The differences that influence each user group in defining their perception of EE make it difficult to assess this construct. However, a systematic review on telerehabilitation in the Philippines (Leochico \& Valera, 2020) ${ }^{[30]}$ discussed that despite the emergence and exploration of these technologies in the Philippines, several challenges continue to hinder their implementation. The study mentions how challenges such as resistance to change, lack of technical knowledge, unclear accountability, limited internet coverage, and lack of laws governing telemedicine prevent the utilization and acceptance of technologies, such as telemedicine and telerehabilitation.

Social Influence (SI) was regarded as the influence of a person or group of people (e.g., family, peers, colleagues, health professionals) to believe that he or she should use telemedicine. According to a study conducted by Kamal et al. (2020) $)^{[31]}$, a positive social influence was deemed to increase the likelihood of acceptance and use of technology. The said study also stated that further research about telemedicine use and the development of stable foundations of trust in telemedicine implementation and performance could enlighten the communities and generate positive feedback for large-scale telemedicine acceptance and use. Pasco (2016) ${ }^{[10]}$ conducted a similar study in the Philippines, focusing on telemedicine physicians' perspectives. The results were analyzed using Pearson correlation analysis, which revealed that SI in physicians had the highest correlation coefficient with behavioral intention to use telemedicine. Thus, SI has been evidently shown to have a significant effect on the users' behavioral intention to use technology due to the strong personal influence of the user's peers and colleagues, according to several sources (Kim et al., 2018; Kim \& Park, 2012; Or et al., 2011) ${ }^{[32][33][34]}$.

In contrast to these findings, the result in this study indicated a weak positive correlation between SI and BI. Additionally, as shown in Table 5, patients have a lower mean score value when compared to the mean value of the physicians. According to Or and Karsh, (2009) ${ }^{[35]}$, the patients' acceptance of technologies could depend on how an influential person or group of people urge or promote to utilize technology. A systematic review conducted by Kijsanayotin et al. (2009) ${ }^{[36]}$ revealed that even though SI has a volatile effect on acceptable behavior, it is still regarded as one of the main constructs of technology acceptance and use. Overall, both user groups exhibited significant correlations between the four constructs and behavioral intention to use telemedicine. Therefore, the researchers accepted the alternative hypothesis $\left(H 3_{a}\right)$.

Rationally, the telemedicine modalities used and preferred by the respondents are dependent on sociodemographic and economic factors. This study, Table 7, indicates that the most used telemedicine modality for both user groups was through social media platforms. Platforms such as Facebook or Viber allow service channels to provide consultations for patients and physicians. The online and mobile aspect of these platforms merits an easy and accessible exchange of image and text information, which permits interactive communication and quick initiation of treatment through viable analysis (Taheri et al., 2020) ${ }^{[37]}$. Accordingly, Table 7 also reveals that the most preferred modality for both physician and patient respondents was also utilizing social media platforms. In the study of O'Neill et al. $(2020)^{[38]}$, the use of social media platforms for telemedicine services based on patients' perspectives was overall positive due to its technology offering more convenient and fluid patient-physician communication. The patients also expressed a preference for 
individualized care that mimics traditional in-person care and a virtual context for the future of online and digital healthcare.

Furthermore, results indicated that video conferencing gathered the 2nd most responses in the preferred modality for both groups. The study by Rush et al. $(2018)^{[39]}$ has stated that video conferencing allows greater diagnostic accuracy and more accurate decision making since it allows an audiovisual patient assessment. However, it is more costly, and the clarity of communication is largely dependent on internet connectivity. Patients with neurocognitive disorder and their caregivers were reported to have improved resilience and wellbeing after experiencing supportive telemedicine via applications with video conference features compared to telemedicine conducted solely by telephone conversation. Video conferencing is perceived to be more user-centered and beneficial as it engages verbal and non-verbal communication for the care recipient and caregiver (Lai et al., 2020) ${ }^{[40]}$.

Figures 2 and 3 display the overall rating of experience in using telemedicine by the user groups. This used a five-point-Likert scale where a score of 1 signifies a very unsatisfied experience. A score of 5 corresponds to a very satisfying experience. Results gathered indicate that the majority of user groups are satisfied with their experience. This possibly dictates that telemedicine's current system and framework implemented in the health institutions provide a functional and acceptable service for both patients and physicians. In addition, this may also indicate that there is potential for telemedicine to be developed even further to convince those who have yet to use this service and to better its execution to existing consumers. With the proposal of House Bill No. 7422 (Philippine E-Health and Telemedicine Development Act of 2020), there is an indication that the local government is aware of the potential that telemedicine may achieve and recognizes that the service would be successful in the future.

It is needless to say that the said claims cannot be generalized to the greater population of Metro Manila using telemedicine. Yet, through exhaustive efforts, the researchers rationalized why the said results came about, suitable at most for the respondents.

\section{Conclusions}

Initially, telemedicine has been regarded as delivering medical care through ICT when distance is a barrier to the healthcare service. However, over time, it has been adopted gradually by more healthcare practitioners and patients; thus, remote healthcare service delivery is no longer only relevant to distant areas. This is especially true in this pandemic which has set telemedicine at the forefront of keeping the essential healthcare services functioning. Also, the need to reduce exposure and in-person care for non-COVID patients has pushed health systems to adopt and implement it. For the said reasons, the researchers have come up with this study which documented the comparison of existing acceptance and use of telemedicine user groups, specifically Filipino physicians and patients, in selected Metro Manila healthcare institutions during the current crisis. Identifying these experiences can explain the acceptance and use of the said technology and know if there's a similarity between the physicians' and patients' telemedicine acceptance and use, especially that this is an emerging technological innovation in healthcare. The following below highlights the results of the study and its importance and implications.

Based on the gathered data, significant correlations were identified between the type of hospital and FC physician user group and the EE of the patient-user group. The majority of the type of hospital for both user groups, a private hospital, presumably contributed to the said correlation. The results imply that the physicians involved in private hospitals believe that organizational and technical infrastructure exists to support telemedicine. In contrast, the patients involved in private hospitals believe that ease is associated with telemedicine since they have different means on how to use telemedicine for their convenience. However, the researchers could not clarify this relationship due to the skewed distribution of private hospitals versus the other types. Given that the type of hospital has not been discussed in the available literature, these findings 
opened a new area that researchers can explore, especially in contexts where the disparity between public and private hospitals is recognizable.

Significant correlations were seen in CA and PE of the physician user group, and CA and FC of the patient user group. Findings suggest that the physicians' anxiety to use telemedicine correlates with their belief that using telemedicine will help them better their job performance. In contrast, patients' anxiety to use telemedicine correlates with their belief that organizational and technical infrastructure exists to support telemedicine. The researchers assert that telemedicine providers and users should consider modalities that are user-friendly to lessen the anxiety of using ICT, thereby maximizing the constructs of telemedicine acceptance and use.

PS has also shown a significant correlation in all of the constructs in both physician and patient user groups. Correlation between PS and EE in physician user groups and correlation between PS and PE in patient user groups were noted showing a significant strong positive correlation. The results imply that the physicians' belief to exchange sensitive or personal health information strongly correlates with their ease of using telemedicine. In contrast, patients' belief to exchange sensitive or personal health information correlates with their belief that using telemedicine will help them better their health. This paper underlines the importance of placing privacy and data integrity as one of the foundations for implementing telemedicine. Providers and consumers will become more confident if the exchange of personal and sensitive information is safeguarded.

The four constructs have shown a significant correlation to BI in both physician and patient user groups. In addition, significant moderate correlations were observed between PE and BI and FC and BI in both user groups. The results indicate that users' intention to use telemedicine correlates with their belief that using telemedicine will help them better their job performance. Furthermore, the users' intention to use telemedicine correlates with their belief that organizational and technical infrastructure exists to support telemedicine. Hence, based on the limited data, the user groups have the same constructs at play on using telemedicine. This study sheds light on what areas of concern may be addressed for future research and policies, given that it presents a promising potential for the Philippine healthcare system.

Additionally, gathered data indicated that telemedicine consultations done through a social media platform were the utilized modality for the majority of both user groups. Moreover, the majority of both user groups selected the social media platform as their preferred modality. With an increase of individuals who possess an internet connection, the number of users exposed to social media increases. Furthermore, the quick and accessible nature of this platform allows for consultations to be easy and interactive. This may indicate that the preference of the user groups may be dependent on the accessibility of the modality.

The overall rating of experience in using telemedicine provided the level of satisfaction undergone by the user groups. The gathered results indicated that most user groups were satisfied with their experience in telemedicine consultations. This accentuates that the existing telemedicine system is of satisfactory levels and that there is potential for the service to improve and better the experience for both user groups.

In totality, the data collected would imply that in recent months, telemedicine generally is a widely accepted form of medical consultation, provided that certain conditions such as proper data security, and organization and technical infrastructure are present in the system. Moreover, this trend would possibly increase as time goes on as the technology is continuously improved and further developed, especially if the need for its use rises as well, such as in the case of the current pandemic.

\section{Recommendations}

Despite the attempt to maximize the circumstance of the study, several limitations were still encountered by the researchers. One of these limitations includes a small sample size acquired, which was largely influenced by the resurgence of COVID-19 cases during the survey proper. Thus, it is recommended that future studies should increase their sample size to broaden the research perspective and yield generalizable 
results. Furthermore, due to the unavailability of respondents, the study had to propose a nonprobability sampling method that selectively chooses the respondents to be involved in the study. However, this sampling method does not eliminate the possibility of bias representation in the study; therefore, researchers who express their intent to explore this topic should consider a probability sampling method in gathering participants. Furthermore, the statistical evaluation and analysis of a probability sampling method could be used to test the significance of a construct and the relationship of the constructs with each other through regression analysis.

Another limitation of this study was the short amount of time allotted for data collection; future researchers may conduct an observational study, whether cross-sectional or longitudinal, to compare different variables simultaneously or determine the distinct changes in the perception of the target population over time. It is also recommended that future studies utilize the structural equation modeling (SEM) statistical analysis technique for the study to determine the moderating effects of the demographic variables and the contextual determinants. Additionally, this aids in determining the positive effects of the constructs of telemedicine acceptance and use on the behavioral intention (BI) of the user groups. Finally, for certain topics which may not have been tackled by the survey questionnaire, it is recommended that future studies supplement the questionnaire with open-ended questions analyzed through qualitative analysis. A mixed-method approach could yield more findings relevant to determining the acceptance and use of telemedicine, which would then be important for implementing future health technologies.

Overall, telemedicine offers a huge potential in optimizing healthcare delivery in the emergence of modern technology. However, with the Philippines' topographic nature, several regions are still in dire need of clinical expertise from health professionals usually available within urban areas. Future studies may direct their attention towards the use of telemedicine present in regional health institutions, especially those extending their services to geographically isolated and disadvantaged areas (GIDA). Furthermore, studying these services may require additional research on data privacy and protection to ensure the safety of the respondents. Discussions on the governing laws and regulations about telemedicine could also help assess the current state of the technology in the country, particularly its policies addressing ethics and data privacy concerns of end-users which could be a topic to consider for future studies.

\section{Acknowledgements}

Throughout the writing of the thesis, the proponents of this study received assistance and instruction from several individuals. Appropriately, the researchers would like to express their appreciation and gratitude to the following individuals:

To their thesis adviser and instructor, Mr. Miguel Carlos G. Arada, RMT, ASCP (IMT), DTA, MSMT, for his commitment to support the group in its endeavor in pursuing the completion of the research. His guidance and feedback have pointed the researchers in the right direction throughout the research process.

To Mr. Viswanath Venkatesh for allowing the researchers to utilize the survey instrument designed from the Unified Theory of Acceptance and Use of Technology. Without this instrument, the objectives sought out by the researchers would not have been attained.

To Ms. Febrina Roy D. Andam, LPT, and Ms. Zea Mai H. San Andres for performing the paper's statistical analysis. Their willingness to respond to questions during consultations allowed the researchers to fully understand the performed analysis.

To the respondents for their participation in the study. Without the responses gathered from these individuals, the study would not have been possible.

To the authors' parents for their continuous support throughout the writing of the paper and for their financial aid. Lastly, the researchers would like to thank God, the Father Almighty. Without His graces and countless blessings, the study would not have been completed. 


\section{References}

[1] World Health Organization (2010). Telemedicine Opportunities and Development in Member States. Retrieved From https://www.who.int/goe/publications/goe_telemedicine_2010.pdf

[2] Craig, J., Patterson, V. \& Wootton, R. (2017). Introduction to telemedicine. CRC Press.

[3] Boxer, R. J., \& Ellimoottil, C. (2019). Advantages and utilization of telemedicine. mHealth, 5, 12. Retrieved from https://doi.org/10.21037/mhealth.2019.04.02

[4] Chen, E. T. (2017). Considerations of Telemedicine in the Delivery of Modern Healthcare. American Journal of Management, 17(3). Retrieved from https://articlegateway.com/index.php/AJM/article/view/1745

[5] Zhang, K., Liu, W. L., Locatis, C., \& Ackerman, M. (2016). Mobile Videoconferencing Apps for Telemedicine. Telemedicine journal and e-health: the official journal of the American Telemedicine Association, $22(1)$, 56-62. https://doi.org/10.1089/tmj.2015.0027

[6] Ting, D. S., Gunasekeran, D. V., Wickham, L., \& Wong, T. Y. (2020, March 1). Next-generation telemedicine platforms to screen and triage. British Journal of Ophthalmology. BMJ Publishing Group. https://doi.org/10.1136/bjophthalmol-2019-315066

[7] Jenkins, J., \& Oyama, O. (2020). Telemedicine: The art of innovative technology in family medicine. International journal of psychiatry in medicine, 55(5), 341-348. https://doi.org/10.1177/0091217420951038

[8] Khatun, F., Palas, Md. J., \& Ray, P. (2017). Using the Unified Theory of Acceptance and Use of Technology model to analyze cloudbased mHealth service for primary care. Digital Medicine, 3(2), 69. https://doi.org/10.4103/digm.digm_21_17

[9] Bashshur, R., \& Shannon, G. (2009). History of Telemedicine Evolution, Context, and Transformation. Mary Ann Liebert Inc. retrieved from https://www.liebertpub.com/doi/abs/10.1089/9781934854112

[10] Pasco, P. M. (2016). Physician User Perspectives in the Practice of Telemedicine in the Philippines. Journal of the International Society for Telemedicine and EHealth, 4, e26 (1-9). Retrieved from https://journals.ukzn.ac.za/index.php/JISfTeH/article/view/172

[11] Cervantes, F. (2020, August 18). Lawmaker bats for dev't of telemedicine, eHealth in PH. Philippine News Agency. Retrieved September 23, 2020, from https://www.pna.gov.ph/articles/1112686

[12] Macabasag, R. L., Magtubo, K. M., \& Marcelo, P. G. (2016). Implementation of Telemedicine Services in Lower-Middle Income Countries: Lessons for the Philippines. Journal of the International Society for Telemedicine and EHealth, 4, e24 (1-11). Retrieved from https://journals.ukzn.ac.za/index.php/JISfTeH/article/view/168

[13] Venkatesh, V., Thong, J. Y. L., \& Xu, X. (2016). Unified theory of acceptance and use of technology: A synthesis and the road ahead. Journal of the Association for Information Systems, 17(5), 328-376. https://doi.org/10.17705/1jais.00428

[14] Acosta, F., Siao, K., \& Resurreccion E. (2020, April 15). Addressing COVID-19 with Healthcare in a Digital Economy. Retrieved from https://www.lexology.com/library/detail.aspx?g=b773868a-86f8-47e4-b6c6-e0b4704d9258

[15] World Health Organization. (2006). World Health Report 2006: Working Together for Health. Geneva: WHO Press; 2006: 1-209

[16] Meghanathan, N. (2016). Assortativity Analysis of Real-World Network Graphs based on Centrality Metrics. Computer and Information Science, 9(3), 7. https://doi.org/10.5539/cis.v9n3p7

[17] Venkatesh, V., Morris, M. G., Davis, G. B., \& Davis, F. D. (2003). User acceptance of information technology: Toward a unified view. MIS Quarterly: Management Information Systems, 27(3), 425-478. https://doi.org/10.2307/30036540

[18] Tsai, J., Cheng, M., Tsai, H., Hung, S., \& Chen, Y. (2019). Acceptance and resistance of telehealth: The perspective of dual-factor concepts in technology adoption. https://doi.org/10.1016/j.ijinfomgt.2019.03.003

[19] Hall, J. L., \& McGraw, D. (2014). For Telehealth To Succeed, Privacy And Security Risks Must Be Identified And Addressed. Health Affairs, 33(2), 216-221. https://doi.org/10.1377/hlthaff.2013.0997

[20] Garg, V., \& Brewer, J. (2011). Telemedicine Security: A Systematic Review. Journal of Diabetes Science and Technology, 5(3), 768-777. https://doi.org/10.1177/193229681100500331

[21] Leochico, C., Espiritu, A. I., Ignacio, S. D., \& Mojica, J. (2020). Challenges to the Emergence of Telerehabilitation in a Developing Country: A Systematic Review. Frontiers in neurology, 11, 1007. https://doi.org/10.3389/fneur.2020.01007

[22] Jalali, M. S., Landman, A., \& Gordon, W. J. (2020). Telemedicine, privacy, and information security in the age of COVID-19. Journal of the American Medical Informatics Association, 28(3), 671-672. https://doi.org/10.1093/jamia/ocaa310

[23] Kohnke, A., Cole, M. L., \& Bush, R. G. (2014). Incorporating UTAUT Predictors for Understanding Home Care Patients' and Clinician's Acceptance of Healthcare Telemedicine Equipment. Journal of Technology Management \&Amp; Innovation, 9(2), 29-41. https://doi.org/10.4067/S0718-27242014000200003

[24] Zhang, Y., Liu, C., Luo, S., Xie, Y., Liu, F., Li, X., \& Zhou, Z. (2019). Factors Influencing Patients' Intentions to Use Diabetes Management Apps Based on an Extended Unified Theory of Acceptance and Use of Technology Model: Web-Based Survey. Journal of Medical Internet Research, 21(8), e15023. https://doi.org/10.2196/15023

[25] Cimperman, M., Brenčič, M.M., \& Trkman, P. (2016). Analyzing older users' home telehealth services acceptance behaviorapplying an Extended UTAUT model. International Journal of Medical Informatics, 90, $22-31$. https://doi.org/10.1016/j.ijmedinf.2016.03.002

[26] Adenuga KI, Iahad NA, Miskon S. Towards reinforcing telemedicine adoption amongst clinicians in Nigeria. Int J Med Inform. 2017 Aug;104:84-96. doi: 10.1016/j.ijmedinf.2017.05.008. Epub 2017 May 17. PMID: 28599820.

[27] Fernandez-Marcelo, P. H., Ongkeko Jr., A. M., Sylim, P. G., Evangelista-Sanchez, A. M., Santos, A. D., Fabia, J. G., Nisperos, G. A., 2016. Formulating the national policy on Telehealth for the Philippines Through Stakeholders' involvement and 
partnership. Acta Medica Philippina, 50(4). doi:10.47895/amp.v50i4.766

[28] Techatraiphum, V., Tharnuraikun, A., Krathu, W., \& Chutimaskul, W. (2016). Telemedicine acceptance framework for the elderly in Thailand. 2016 International Conference on Information and Communication Technology Convergence (ICTC). doi:10.1109/ictc. 2016.7763430

[29] Sun, Y., Wang, N., Guo, X., \& Peng, Z. (2013). Understanding The Acceptance Of Mobile Health Services: A Comparison And Integration Of Alternative Models. Journal of Electronic Commerce Research, 14(2), 183-200. https://csulb.edu/journals/jecr/issues/20132/paper4.pdf

[30] Leochico, C. F., Valera, M. J., 2020. Follow-up consultations through telerehabilitation for wheelchair recipients with paraplegia in a developing country: A case report. Spinal Cord Series and Cases, 6(1). doi:10.1038/s41394-020-0310-9

[31] Kamal, S. A., Shafiq, M., \& Kakria, P. (2020). Investigating acceptance of telemedicine services through an extended technology acceptance model (TAM). Technology in Society, 60(101212), 1-10. https://doi.org/10.1016/j.techsoc.2019.101212.

[32] Kim, E. H., Gellis, Z. D., Bradway, C. K., \& Kenaley, B. (2018). Depression care services and TELEHEALTH technology use for homebound elderly in the United States. Aging \& Mental Health, 23(9), 1164-1173. doi:10.1080/13607863.2018.1481925

[33] Kim, J., \& Park, H. (2012). Development of a health information technology acceptance model using consumers' health behavior intention. Journal of Medical Internet Research, 14(5). doi:10.2196/jmir.2143

[34] Or, C. K., Karsh, B., Severtson, D. J., Burke, L. J., Brown, R. L., \& Brennan, P. F. (2011). Factors affecting home care patients' acceptance of a web-based interactive self-management technology. Journal of the American Medical Informatics Association, 18(1), 51-59. doi:10.1136/jamia.2010.007336

[35] Or, C. K., \& Karsh, B. (2009). A systematic review of patient acceptance of consumer health information technology. Journal of the American Medical Informatics Association, 16(4), 550-560. doi:10.1197/jamia.m2888

[36] Kijsanayotin, B., Pannarunothai, S., \& Speedie, S. M. (2009). Factors influencing health information technology adoption in Thailand's community HEALTH centers: Applying the UTAUT MODEL. International Journal of Medical Informatics, 78(6), 404-416. doi:10.1016/j.ijmedinf.2008.12.005

[37] Taheri, M. S., Falahati, F., Radpour, A., Karimi, V., Sedaghat, A., \& Karimi, M. A. (2020). Role of social media and telemedicine in diagnosis \& management of COVID-19; An experience of the Iranian society of radiology. Archives of Iranian Medicine, 23(4), 285-286. https://doi.org/10.34172/aim.2020.15

[38] O'Neill, P., Shandro, B., \& Poullis, A. (2020, October). Patient perspectives on social-media-delivered telemedicine for inflammatory bowel disease. Retrieved from https://www.ncbi.nlm.nih.gov/pmc/articles/PMC7571747/

[39] Rush, K. L., Howlett, L., Munro, A., \& Burton, L. (2018). Videoconference compared to telephone in healthcare delivery: A systematic review. International Journal of Medical Informatics, 118, 44-53. doi: 10.1016/j.ijmedinf.2018.07.007

[40] Lai, F., Yan, E., Yu, K., Tsui, W., Chan, D., \& Yee, B. (2020, November). The protective impact of telemedicine on persons with dementia and their caregivers during the covid-19 pandemic. Retrieved from https://www.ncbi.nlm.nih.gov/pmc/articles/PMC7413846/ 


\section{Appendix A. Correlation between Demographic Variables and Constructs of Telemedicine Acceptance and Use}

Table 2.1. Correlation of Physician User Group's Demographic Variables and Constructs of Telemedicine Acceptance and Use

\begin{tabular}{|c|c|c|c|c|c|c|c|c|c|c|}
\hline \multirow{3}{*}{$\begin{array}{c}\text { Demographic } \\
\text { Variables } \\
\end{array}$} & \multicolumn{10}{|c|}{ Constructs ${ }_{P a t i e n t}$} \\
\hline & \multicolumn{3}{|c|}{$\mathrm{PE}$} & \multicolumn{3}{|c|}{$\mathrm{EE}$} & \multicolumn{3}{|c|}{ SI } & \\
\hline & $\rho$ & $\begin{array}{c}\text { Level of } \\
\text { Correlation }\end{array}$ & $p$-value & $\rho$ & $\begin{array}{c}\text { Level of } \\
\text { Correlation }\end{array}$ & $p$-value & $\rho$ & $\begin{array}{c}\text { Level of } \\
\text { Correlation }\end{array}$ & $p$-value & $\rho$ \\
\hline $\operatorname{Age}^{* *}$ & 0.0516715 & $\begin{array}{c}\text { Very Weak } \\
\text { Positive }\end{array}$ & 0.695 & $\begin{array}{c}- \\
0.005079 \\
979\end{array}$ & $\begin{array}{c}\text { Very Weak } \\
\text { Negative }\end{array}$ & 0.9693 & 0.03201961 & $\begin{array}{c}\text { Very Weak } \\
\text { Positive }\end{array}$ & 0.8081 & $\begin{array}{c}0.0823319 \\
5\end{array}$ \\
\hline & $\varphi_{\mathrm{c}}$ & $\begin{array}{c}\text { Level of } \\
\text { Correlation }\end{array}$ & $p$-value & $\varphi_{\mathrm{c}}$ & $\begin{array}{c}\text { Level of } \\
\text { Correlation }\end{array}$ & $p$-value & $\varphi_{\mathrm{c}}$ & $\begin{array}{c}\text { Level of } \\
\text { Correlation }\end{array}$ & $p$-value & $\varphi_{\mathrm{c}}$ \\
\hline Sex $* * *$ & 0.47 & $\begin{array}{l}\text { Moderate } \\
\text { Positive }\end{array}$ & 0.211 & 0.351 & $\begin{array}{c}\text { Weak } \\
\text { Positive }\end{array}$ & 0.766 & 0.508 & $\begin{array}{l}\text { Moderate } \\
\text { Positive }\end{array}$ & 0.279 & 0.458 \\
\hline Location & - & - & - & - & - & - & - & - & - & - \\
\hline $\begin{array}{l}\text { Type of } \\
\text { Hospital } * * *\end{array}$ & 0.543 & $\begin{array}{l}\text { Moderate } \\
\text { Positive }\end{array}$ & 0.061 & 0.562 & $\begin{array}{l}\text { Moderate } \\
\text { Positive }\end{array}$ & 0.062 & 0.403 & $\begin{array}{l}\text { Moderate } \\
\text { Positive }\end{array}$ & 0.714 & 0.599 \\
\hline
\end{tabular}


Table 2.2. Correlation of Patient User Group's Demographic Variables and Constructs of Telemedicine Acceptance and Use

\begin{tabular}{|c|c|c|c|c|c|c|c|c|c|c|}
\hline \multirow{3}{*}{$\begin{array}{l}\text { Demographic } \\
\text { Variables } \\
\end{array}$} & \multicolumn{10}{|c|}{ ConstructsPatient } \\
\hline & \multicolumn{3}{|c|}{$\mathrm{PE}$} & \multicolumn{3}{|c|}{$\mathrm{EE}$} & \multicolumn{3}{|c|}{ SI } & \multirow[b]{2}{*}{$\rho$} \\
\hline & $\rho$ & $\begin{array}{c}\text { Level of } \\
\text { Correlation }\end{array}$ & $p$-value & $\rho$ & $\begin{array}{c}\text { Level of } \\
\text { Correlation }\end{array}$ & $p$-value & $\rho$ & $\begin{array}{c}\text { Level of } \\
\text { Correlation }\end{array}$ & $p$-value & \\
\hline Age** $^{* *}$ & $\begin{array}{c}- \\
0.02904298\end{array}$ & $\begin{array}{c}\text { Very Weak } \\
\text { Negative }\end{array}$ & 0.8257 & $\begin{array}{c}- \\
0.245861\end{array}$ & $\begin{array}{c}\text { Weak } \\
\text { Negative }\end{array}$ & 0.05829 & 0.1144463 & $\begin{array}{c}\text { Very Weak } \\
\text { Positive }\end{array}$ & 0.3839 & $\begin{array}{c}- \\
0.1504362\end{array}$ \\
\hline & $\varphi_{c}$ & $\begin{array}{c}\text { Level of } \\
\text { Correlation }\end{array}$ & $p$-value & $\varphi_{\mathrm{c}}$ & $\begin{array}{c}\text { Level of } \\
\text { Correlation }\end{array}$ & $p$-value & $\varphi_{\mathrm{c}}$ & $\begin{array}{c}\text { Level of } \\
\text { Correlation }\end{array}$ & $p$-value & $\varphi_{\mathrm{c}}$ \\
\hline Sex*** & 0.331 & $\begin{array}{c}\text { Weak } \\
\text { Positive }\end{array}$ & 0.765 & 0.307 & $\begin{array}{c}\text { Weak } \\
\text { Positive }\end{array}$ & 0.844 & 0.444 & $\begin{array}{l}\text { Moderate } \\
\text { Positive }\end{array}$ & 0.619 & 0.456 \\
\hline Location $* * *$ & 0.336 & $\begin{array}{c}\text { Weak } \\
\text { Positive }\end{array}$ & 0.745 & 0.402 & $\begin{array}{l}\text { Moderate } \\
\text { Positive }\end{array}$ & 0.464 & 0.56 & $\begin{array}{l}\text { Moderate } \\
\text { Positive }\end{array}$ & 0.172 & 0.177 \\
\hline $\begin{array}{l}\text { Type of } \\
\text { Hospital*** }\end{array}$ & 0.541 & $\begin{array}{l}\text { Moderate } \\
\text { Positive }\end{array}$ & 0.063 & 0.602 & $\begin{array}{l}\text { Strong } \\
\text { Positive }\end{array}$ & $0.016 *$ & 0.452 & $\begin{array}{l}\text { Moderate } \\
\text { Positive }\end{array}$ & 0.587 & 0.446 \\
\hline
\end{tabular}


Appendix B. Range correlation coefficient values and the corresponding levels of correlation

Table 9. Range of Correlation Coefficient Values and the Corresponding Levels of Correlation

\begin{tabular}{cccc}
\hline $\begin{array}{c}\text { Range of Correlation } \\
\text { Coefficient Values }\end{array}$ & Level of Correlation & $\begin{array}{c}\text { Range of Correlation } \\
\text { Coefficient Values }\end{array}$ & Level of Correlation \\
\hline 0.80 to 1.00 & Very Strong Positive & -1.00 to -0.80 & Very Strong Negative \\
0.60 to 0.79 & Strong Positive & -0.79 to -0.60 & Strong Negative \\
0.40 to 0.59 & Moderate Positive & -0.59 to -0.40 & Moderate Negative \\
0.20 to 0.39 & Weak Positive & -0.39 to -0.20 & Weak Negative \\
0.00 to 0.19 & Very Weak Positive & -0.19 to -0.01 & Very Weak Negative \\
\hline
\end{tabular}

